\title{
Hubungan Kualitas Pelayanan Keperawatan Dengan Kepuasan Pasien Pengguna BPJS di RSUD Panembahan Senopati Bantul
}

\author{
Imram Radne Rimba Putri \\ Universitas Alma Ata \\ EMail: imramradne@gmail.com
}

\begin{abstract}
Abstrak
BPJS merupakan lembaga yang dibentuk untuk menyelenggarakan program jaminan sosial di Indonesia. Sebagai suatu sistem yang besar dan baru berlangsung dalam tempo yang relatif singkat banyak ditemukan keluhan pasien tentang sistem dan pelayanan kesehatan yang diterapkan oleh BPJS Kesehatan, salah satu contohnya terkait sistem rujukan berjengjangnya. Hal tersebut dapat saja berpengaruh kepada kepuasan pasien. Kondisi yang demikian membuat rumah sakit harus selalu menjaga kualitas pelayanannya. Penelitian ini bertujuan untuk mengetahui hubungan kualitas pelayanan keperawatan dengan kepuasan pasien yang menggunakan BPJS di RSUD Panembahan Senopati Bantul. Metode penelitian ini deskriptif kuantitatif dengan rancangan cross sectional. Populasi dalam penelitian ini adalah pasien yang berada di ruang ranap kelas III di RSUD Panembahan Senopati Bantul. Sampel pada penelitian ini adalah pasien BPJS berjumlah 90 . Analisa data pada penelitian ini untuk uji korelasi menggunakan uji statistik Kendal tau. Berdasarkan hasil penelitian maka diperoleh data terdapat hubungan yang lemah antara kualitas pelayanan keperawatan dengan kepuasan pasien BPJS diruangranap kelas III di RSUD Panembahan Senopati Bantul dengan nilai 0,001 dan $r=0,337$. Kesimpulannya terdapat hubungan yang lemah antara kualitas pelayanan keperawatan dengan kepuasan pasien BPJS.
\end{abstract}

Kata Kunci: Kualitas pelayanan, Kepuasan pasien, Pasien BPJS

\section{The Correlation Between the Quality of Nursing Servce And Patient satisfaction Using BPJS at Panembahan Senopati Hospital, Bantul}

\begin{abstract}
Abstrack
BPJS is a national agency established to organize social security programs in Indonesia. As a large and new system took place within a relatively short period of time, complaints were made about the system and health services implemented by BPJS Kesehatan. There were many participants of the BPJS Kesehatan who complained about the leveled referral service system applied by the BPJS Kesehatan. This will certainly influence the patient satisfaction. Such conditions have made hospitals always maintain the quality of their services. The aim of this research is to determine the correlation between the quality of nursing service and satisfaction of BPJS at Panembahan Senopati Hospital, Bantul.This research applies quantitative descriptive research with cross sectional design. Population of this research is patients in the 3rd class inpatient care rooms at Panembahan Senopati Hospital, Bantul. Sample in this research for BPJS patients is 90. Data analysis in this study for correlation test using statistic test Kendal tau. Based on the result of the research, it is found that there is a weak correlation between quality of nursing service and patient satisfaction of BPJS in the 3rd class inpatient care room at Panembahan Senopati Hospital, Bantul with 0.001 and $r=$ 0.337. There is a weak correlation between quality of nursing service, patients of BPJS satisfaction.
\end{abstract}

Keywords: Service quality, Patient satisfaction, Patients of BPJS

Received: 30/08/2018; published: 28/10/2018 


\section{PENDAHULUAN}

Rumah sakit (RS) merupakan penyedia pelayanan kesehatan yang komprehensif dan holistik, yaitu pelayanan kesehatan yang meliputi promotif, preventif, kuratif dan rehabilitatif (1). Kompleksitas pelayanan kesehatan tersebut menuntut RS untuk selalu meningkatkan kualitas pelayanannya. Salah satu usaha yang dilakukan dengan cara bekerja sama dengan program pemerintah penyelenggara jaminan Kesehatan yaitu Sistem Jaminan Sosial Nasional (SJSN) yang bersifat wajib berdasarkan Undang-Undang No.40 Tahun 2004. Tujuannya adalah agar semua penduduk Indonesia terlindungi dalam sistem asuransi khususnya asuransi kesehatan. Penyelenggaraan pelayanan kesehatan meliputi semua fasilitas kesehatan yang bekerjasama dengan Badan Penyelenggara Jaminan Sosial (BPJS) kesehatan.

BPJS Kesehatan sebelumnya bernama Askes (Asuransi Kesehatan), yang dikelola oleh PT Askes Indonesia (Persero), namun sesuai UU No. 24 Tahun 2011 tentang BPJS, PT. Askes Indonesia berubah menjadi BPJS Kesehatan. Dalam masa peralihan ini tentu beresiko dapat menyebabkan adanya perbedaan pelayanan yang diterima oleh pasien karena dalam sistem pelayanan BPJS terdapat mekanisme pelayanan kesehatan rujukan berjenjang dan hal tersebut akan berpengaruh terhadap kepuasan pasien. Sistem pelayanan rujukan berjenjang ini juga menjadi tantangan yang kerap dihadapi pasien peserta BPJS Kesehatan di RSUD Panembahan Senopati. RSUD Panembahan Senopati Bantul juga bekerja sama dengan BPJS.

Kepuasan pasien merupakan tanggapan terhadap terpenuhinya kebutuhan sesuai harapan pasien (3). Penelitian ini akan berfokus pada pelayanan dalam keperawatan, Karena perawat merupakan salah satu komponen penting dalam pelayanan pasien di RS (4). Walaupun selain mengutamakan kepuasan pasien, RS juga harus mengutamakan kepuasan perawatnya, agat motivasi kerjanya juga tinggi, hal tersebut didukung oleh penelitian terdahulu tentang motivasi kerja perawat yang ditinjau dengan teori motivasi ERG dari Alderfer di RS PKU Muhammadiyah Yogyakarta Unit II, dengan hasilnya sebagian besar motivasi kerja perawat berada dikategori tinggi dan berpengaruh terhadap kepuasan kerja perawat (5).

Berdasarkan hasil studi pendahuluan yang dilakukan oleh peneliti pada tanggal 02 November 2017 di RSUD Panembahan Senopati Bantul, didapatkan data bahwa pada tahun 2015 sampai tahun 2017 pasien rawat inap (ranap) kelas I, II, dan III yang menggunakan BPJS mengalami penurunan setiap tahunnya. Pada tahun 2015 jumlah pasien yang menggunkan BPJS sebanyak 17.514 pasien dan pada tahun 2017 menjadi sebanak 13.136 pasien. Sedangkan pasien ranap kelas I, II, dan III yang tidak menggunakan BPJS atau Non BPJS pada tahun 2015 ke tahun 2016 mengalami peningkatan yaitu pada tahun 2015 jumlah 
pasien sebanyak 5.657 pasien, pada tahun 2016 sebanyak 6.221 pasien. Berdasarkan data diatas, dapat diketahui bahwa jumlah pasien yang menggunakan BPJS mengalami penurunan setiap tahunnya dan pasien yang tidak menggunakan BPJS atau Non-BPJS pada tahun 2015 ke tahun 2016 mengalamikenaikan. Hal tersebut menjadikan dasar peneliti dalam mengetahui hubungan kualitas pelayanan keperawatan dengan kepuasan pasien BPJS Di ruang ranap RSUD Panembahan Senopati Bantul, agar dapat digunakan sebagai perbaikan terhadap pelayanan keperawatan di ruang ranap RSUD Panembahan Senopati Bantul dengan lebih baik. Penelitian ini juga didukung oleh penelitian terdahulu, dengan hasilnya menunjukkan adanya keeratan hubungan antara mutu pelayanan rumah sakit dengan kepuasan pasien BPJS Kesehatan di instalasi ranap kelas III RSUD Panembahan Senopati Bantul.

\section{BAHAN DAN METODE}

Jenis penelitian ini merupakan penelitian deskriptif kuantitatif dengan menggunakan rancangan cross sectional, dilakukan di bangsal ranap kelas III, yaitu Ruang Melati, Ruang Bakung, Ruang Flamboyan dan Ruang Bougenvil di RSUD Panembahan Senopati Bantul, pada bulan Januari tahun 2018. Populasi dalam penelitian ini adalah pasien yang berada di ruang ranap kelas III di RSUD Panembahan Senopati Bantul sebanyak 116 pasien. Tehnik pengambilan sampel secara accidental sampling dan penentuan besar sampel menggunakan rumus Slovin didapat jumlah sampel 90 pasien. Analisa data dalam penelitian ini menggunakan analisis univariat untuk mengetahui frekuensi dan distribusi variable penelitian, dan bivariat dengan uji stastistik Kendal tau.

\section{HASIL DAN PEMBAHASAN}

Karakteristik Responden Pasien BPJS

Dalam penelitian ini, karakteristik responden pasien BPJS terdiri dari jenis kelamin, usia responden, pendidikan terakhir responden dan pekerjaan responden. Maka diperoleh data sebagai berikut pada Tabel 1. Berdasarkan Tabel 1 distribusi frekuensi karakteristik responden BPJS yang paling banyak yaitu berjenis kelamin perempuasn sebanyak 47 orang $(52,2 \%)$ dan paling sedikit berjenis kelamin laki-laki sebanyak 43 orang $(47,8 \%)$. Dari segi usia yang paling banyak berusia lebih dari 50 tahun sebanyak 46 orang $(51,1 \%)$ dan yang paling sedikit berusia 31-40 tahun sebanyak 5 orang (5,6\%). Dari segi pendidikan yang paling banyak 39 orang $(43,3 \%)$ adalah pendidikan SD dan yang paling sedikit berjumlah 1 orang $(1,1 \%)$ adalah pendidikan S2. Pekerjaan terbanyak berjumlah 34 orang $(37,8 \%)$ yaitu bekerjan sebagai lainnya, disini seperti ibu rumah tangga, petani dan buruh, sedangkan pekerjaan yang paling sedikit berjumlah 2 orang $(2,2 \%)$ yaitu bekerja sebagai TNI/POLRI. 
Tabel 1. Distribusi Frekuensi Karakteristik Responden BPJS Rawat Inap Kelas III di RSUD Panembahan Senopati Bantul

\begin{tabular}{llcc}
\hline & Karakterisik & n (90) & $\%$ \\
\hline Jenis Kelamin & Laki-Laki & 43 & 47,8 \\
& Perempuan & 47 & 52,2 \\
\hline Usia & $<20$ & 12 & 13,3 \\
& $21-30$ & 8 & 8,9 \\
& $31-40$ & 5 & 5,6 \\
& $41-50$ & 19 & 21,1 \\
& $>50$ & 46 & 51,1 \\
\hline Pendidikan & Tidak Sekolah & 9 & 10,0 \\
& SD & 39 & 43,3 \\
& SMP & 4 & 4,4 \\
& SMU & 8 & 8,9 \\
& Diploma & 17 & 18,9 \\
& S1 & 12 & 13,3 \\
& S2 & 1 & 1,1 \\
\hline Pekerjaan & Tidak Bekerja & 14 & 15,6 \\
& PNS/ TNI/POLRI & 14 & 15,5 \\
& Pegawai Swasta & 4 & 4,4 \\
& Pelajar/Mahasiswa & 7 & 7,8 \\
& Wiraswasta & 17 & 18,9 \\
& Lainnya & 34 & 37,8 \\
\hline
\end{tabular}

Kualitas Pelayanan Keperawatan Pasien BPJS

Tabel 2. Distribusi Frekuensi Kualitas Pelayanan Keperawatan Pasien BPJS Rawat Inap kelas III di RSUD Panembahan Senopati Bantul

\begin{tabular}{lll}
\hline Kualitas & $\mathbf{n}$ & $\%$ \\
\hline Baik & 30 & 33,3 \\
Cukup & 49 & 54,4 \\
Buruk & 11 & 12,2 \\
\hline Total & $\mathbf{9 0}$ & $\mathbf{1 0 0 , 0}$ \\
\hline
\end{tabular}

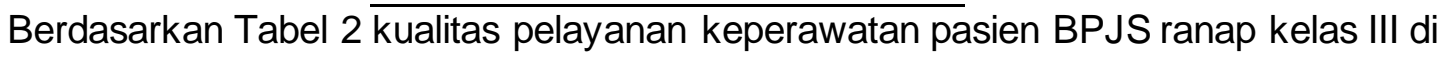
RSUD Panembahan Senopati Bantul tergolong cukup baik, dimana sebanyak 49 (54,4\%) pasien mengatakan kualitas pelayanan keperawatan pasien BPJS ranap kelas III cukup baik. Meningkatkan kualitas pelayanan keperawatan merupakah hal yang cukup penting bagi sebuah rumah sakit, karena kualitas pelayanan yang baik akan menciptakan kepuasan yang tinggi bagi pasien. Berdasarkan hasil penelitian tersebut, diharapkan dapat memberikan kontribusi dari pelayanan keperawatan yang ada di RSUD Panembahan Senopati Bantul, sehingga dapat meningkatkan kepuasan pasien dan meningkatkan kepercayaan pasien dalam menggunakan jasa pelayanan kesehatan khususnya pelayanan keperawatan di RSUD Panembahan Senopati Bantul.

Menurut hasil penelitian terdahulu, hasilnya mengatakan bahwa semakin baik kualitas pelayanan kesehatan yang diberikan maka akan semakin tinggi pula tingkat kepuasan yang dirasakan oleh pasien. Rumah sakit sebagai penyedia layanan kesehatan yang kompleks tentunya menjadi harapan besar untuk dapat meningkatkan derajat kesehatan bagi 
masyarakat. Jika pelayanan yang diberikan rumah sakit dirasakan baik oleh pasien maka akan memicu pasien kembali menggunakan jasa pelayanan tersebut saat mereka membutuhkannya (6).

Kepuasan Pasien BPJS

Tabel 3. Distribusi Frekuensi Kepuasan Pasien BPJS Rawat Inap kelas III di RSUD Panembahan Senopati Bantul 2018

\section{Sumber: Data Primer 2018}

\begin{tabular}{lll}
\hline $\begin{array}{l}\text { Kepuasan } \\
\text { Pasien }\end{array}$ & $\mathbf{n}$ & $\%$ \\
\hline Baik & 27 & 30,0 \\
Cukup & 46 & 51,1 \\
Buruk & 17 & 18,9 \\
\hline Total & 90 & 100,0 \\
\hline
\end{tabular}

Berdasarkan Tabel 3 kepuasan pasien BPJS ranap kelas III di RSUD Panembahan Senopati Bantul tergolong cukup baik, dimana dari 90 responden paling banyak mengatakan cukup puas yaitu sebanyak 46 orang $(51,1 \%)$. Kepuasan merupakan salah satu indikator untuk mengukur keberhasilan dalam pelayanan rumah sakit yang bermanfaat memberikan feedback bagi pihak manajemen (7). Maka dapat disimpulkan bahwa perasaan puas yang dirasakan pasien merupakan perasaan yang timbul karena apa yang pasien harapkan, didapatkannya dirumah sakit. Kepuasan pasien juga akan meningkat dengan sendirinya jika kualitas pelayanan keperawatan di RSUD Panembahan Senopati Bantul ditingkatkan. Menurut penelitian yang dilakukan oleh Tirtanadi Sodik tahun 2016 yang berjudul 'Gambaran Kepuasan Pasien BPJS dan non BPJS Terhadap Kualitas Pelayanan Kesehatan Gigi dan Mulut di Puskesmas Umbulharjo II mengatakan bahwa apabila harapannya terpenuhi berarti pelayanan tersebut telah 4 Pasien BPJS.

Tabel 4. Kualitas Pelayanan Keperawatan dengan Kepuasan Pasien BPJS Rawat Inap Kelas III di RSUD Panembahan Senopati Bantul 2018

\begin{tabular}{|c|c|c|c|c|c|c|c|c|c|c|c|c|c|c|}
\hline \multirow{3}{*}{$\begin{array}{c}\text { Kualitas } \\
\text { Pelayanan } \\
\text { Keperawata } \\
\mathbf{n}\end{array}$} & \multicolumn{8}{|c|}{ Kepuasan pasien } & \multirow{2}{*}{\multicolumn{3}{|c|}{ Total }} & \multirow[t]{3}{*}{$\mathbf{r}$} & \multirow{3}{*}{\multicolumn{2}{|c|}{$\begin{array}{c}\mathbf{P} \\
\text { Value }\end{array}$}} \\
\hline & \multicolumn{2}{|c|}{ Baik } & \multicolumn{3}{|c|}{ Cukup } & \multicolumn{3}{|c|}{ Buruk } & & & & & & \\
\hline & $\mathbf{n}$ & $\%$ & $\mathbf{n}$ & $\%$ & & $\mathbf{n}$ & & $\%$ & $\mathbf{n}$ & \multicolumn{2}{|c|}{$\%$} & & & \\
\hline Baik & 14 & 15,6 & $\overline{14}$ & & 15,6 & & 2 & 2,2 & & 30 & 33,3 & & 0,337 & 0,001 \\
\hline Cukup & 12 & 13,3 & 28 & & 31,1 & & 9 & 10,0 & & 49 & 54,4 & & & \\
\hline Buruk & 1 & 1,1 & 4 & & 4,4 & & 6 & 6,7 & & 11 & 12,2 & & & \\
\hline Total & 27 & 30 & & 46 & & 51,1 & & 17 & 18,9 & & 90 & 100 & & \\
\hline
\end{tabular}

Sumber: Data Primer 2018

Berdasarkan Tabel 4 tabulasi silang antara kualitas pelayanan keperawatan dengan kepuasan pasien BPJS, kualitas pelayanan cukup baik sebanyak 49 (54,4\%) orang dan sebanyak 12 (13,3\%) orang mengatakan sangat puas dengan pelayanan keperawatan, dan yang mengatakan cukup puas dengan pelayanana keperawatan sebanyak $28(31,1 \%)$ orang. Sedangkan yang mengatakan tidak puas dengan pelayanan keperawatan sebanyak 9 Putri, I.R.R. 2018. Indonesian Journal of Hospital Administration 
$(10,0 \%)$ orang. Berdasarkan Uji statisti didapatkan nilai $r=0,337$ dengan nilai $p=0,001$ yang artinya terdapat hubungan antara kualitas pelayanan keperawatan dengan kepuasan pasien ranap kelas III yang menggunakan BPJS di RSUD Panembahan Senopati Bantul, dengan keeratan hubungan lemah. Kualitas pelayanan yang baik merupakan faktor yang penting dalam salah satu usaha menciptakan kepuasan konsumen. Pelayanan yang baik, yang diberikan oleh perawat kepada pasien sehingga menciptakan pasien puas terhadap pelayanan keperawatan yang diberikan oleh rumah sakit (9). Kepuasan adalah gagasan emosional yang dapat mempengaruhi penilaian jasa yang disediakan termaksud kualitas pelayanan yang ada di rumah sakit (10).

Berdasar uji stastistik didapatkan nilai $r=0,337$ dengan nilai $p=0,001$ yang artinya terdapat hubungan antara kualitas pelayanan keperawatan dengan kepuasan pasien ranap kelas III yang menggunakan BPJS di RSUD Panembahan Senopati Bantul, dengan keeratan hubungan lemah, antara kualitas pelayanan keperawatan dengan kepuasan pasien BPJS ranap kelas III RSUD Panembahan Senopati Bantul dan beberapa faktor yang mempengaruhi keeratan tersebut salah satunya yaitu sikap perawat. Menurut pasien, perawat dalam memberikan pelayanan keperawatan sudah cepat tanggap, hanya saja dalam pemberian pelayanan keperawatannya perawat kurang ramah. Jika dihubungkan antara kualitas pelayanan keperawatan dengan kepuasan pasien terjawab kenapa kualitas pelayanan keperawatan dan kepuasan pasien sama-sama berada pada tingkat cukup. Pasien dalam menerima pelayanan keperawatan cukup puas karena perawat kompeten dalam memberikan pelayanan keperawatan hanya saja proses pemberiannya perawat kurang ramah. Berdasarkan hasil dari penelitian ini maka dapat diketahui bahwa penelitian ini sesuai dengan hipotesis awal, yaitu terdapat hubungan antara kualitas pelayanan keperawatan dengan kepuasan pasien BPJS di RSUD Panembahan Senopati Bantul.

\section{SIMPULAN DAN SARAN}

\section{Kesimpulan}

Ada pengaruh yang signifikan iklim organisasi, kepemimpinan terhadap motivasi kerja perawat di RS PKU Muhammadiyah Yogyakarta Unit II. Ada pengaruh yang signifikan motivasi kerja, iklim organisasi, kepemimpinan terhadap kinerja perawat di RS PKU Muhammadiyah Yogyakarta Unit II.

Pengaruh iklim organisasi terhadap kinerja perawat merupakan pengaruh langsung. Pengaruh kepemimpinan terhadap kinerja perawat merupakan pengaruh langsunBerdasarkan hasil penelitian, Karakteristik responden pasien BPJS paling banyak berjenis kelamin perempuan dan berusia $>50$ tahun. Dari segi pendidikan, presentase tertinggi yaitu berpendidikan SD dan dari segi pekerjaan presentase tertinggi yaitu bekerja sebagai lainnya. Kualitas pelayanan ranap kelas III pasien BPJS tergolong cukup baik. 
Tingkat kepuasan pasien BPJS diruang ranap kelas III di RSUD Panembahan Senopati Bantul dalam kategori cukup puas. Kesimpulan dati penelitian ini adalah terdapat hubungan yang lemah antara kualitas pelayanan keperawatan dengan kepuasan pasien BPJS di RSUD Panembahan Senopati Bantul.

\section{Saran}

Saran yang dapat disampaikan kepada pihak manajemen rumah sakit adalah, untuk selalu memperhatikan kualitas pelayanan khususnya pelayanan keperawatan agar kepuasan pelanggan tetap terjaga. ataupun menjaga dan mengoptimalkan pelayanan yang sudah bagus, baik pelayanan untuk pasien umum ataupun pasien dengan BPJS.

\section{DAFTAR PUSTAKA}

1. Republik Indonesia. 2009. Undang-Undang RI Nomor 44 Tahun 2009 tentang Rumah Sakit.

2. Undang Undang RI Nomor 52 Tahun 2009 tentang Kesehatan.

3. Koentjoro, Tjahjono. (2007). Regulasi Kesehatan di Indonesia. Yogyakarta: Penerbit ANDI.

4. Asmuji. 2012. Manajemen Keperawatan Konsep dan Aplikasi. Jogjakarta. Arruzz Media.

5. Putri, I. R. R., \& Rosa, E. M. (2015). Analisis Motivasi Kerja Perawat di Ruang Ranap RS PKU Muhammadiyah Yogyakarta Unit II. Jurnal Ners dan Kebidanan Indonesia, 3(2), 8290.

6. Sri yuniarti. Hubungan Antara Kualitas Pelayanan Rumah Sakit dengan Tingkat Kepuasan Pasien BPJS di Ruang Perawatan RSUD Sultan Syarif Mohamad Alkadrie Kota Pontianak. [Internet] 2015. Available From: http://jurnal.untan.ac.id/index.php/jmkeperawatanFK/article/view/11039

7. Nursalam. (2011). Manajemen Keperawatan.edisi 3. Jakarta: Salemba Medika.

8. Tirtanadi, S. Gambaran Kepuasan Pasien BPJS dan Non BPJS Terhadap Kualitas Pelayanan Kesehatan Gigi dan Mulut di Puskesmas Umbulharjo II. [Internet] 2016. Available From: http://repository.umy.ac.id/handle/123456789/2842

9. Muninjaya, A. A. 2012. Manajemen Mutu Pelayanan Kesehatan. Jakarta: EGC

10. Satrianegara, 2009. Buku Ajar Organisasi dan Manajemen Pelayanan Kesehatan serta Kebidanan. Salemba Medika. Jakarta. 